\title{
Idiopathic Pulmonary Fibrosis: Recent Trials and Current Drug Therapy
}

\author{
Mark G. Jones $^{\mathrm{a}}$ Sophie Fletcher ${ }^{\mathrm{b}}$ Luca Richeldi ${ }^{\mathrm{a}, \mathrm{c}}$ \\ ${ }^{a}$ Academic Unit of Clinical and Experimental Sciences, University of Southampton Faculty of Medicine, \\ ${ }^{\mathrm{b}}$ Department of Respiratory Medicine, University Hospital Southampton, and ${ }^{\mathrm{C}}$ Respiratory Biomedical Research \\ Unit, National Institute for Health Research, University Hospital Southampton, Southampton, UK
}

\begin{abstract}
Idiopathic pulmonary fibrosis (IPF) is a chronic fibrotic lung disease with increasing incidence; the median survival is only 35 months and as yet no therapy has been proven to prolong survival. Recent unexpected randomised controlled trial $(R C T)$ results and the conflicting evaluations of drug efficacy by regulatory agencies when considering the approval of pirfenidone have emphasised that we remain in the first stages of both our understanding of disease-relevant therapeutic targets and in our ability to investigate these putative targets with well-designed RCT. Three phase III trials are, however, anticipated to report results in 2014 and there is cautious optimism that we may be entering an era of mechanism-based anti-fibrotic therapies proven by large RCT to modify disease progression. We must now address how to practically translate these therapies safely and with maximal efficacy from a homogenous RCT population to the 'real-life' heterogeneous population of patients with IPF. The role of a formal multi-disciplinary team meeting in a specialist centre with expertise in IPF is key to this. New methodological and ethical research challenges will arise as we enter an era of potential combination therapy; standardized, robust RCT design will be central to meeting these challenges if we are to enable ongoing progress in our aim of increasing both the length and quality of life of patients with IPF.
\end{abstract}

(c) 2013 S. Karger AG, Basel

\section{Introduction}

Idiopathic pulmonary fibrosis (IPF) is a complex chronic fibroproliferative disease of unknown aetiology characterised by progressive accumulation of extracellular matrix within the pulmonary interstitium. It is progressive and irreversible with an estimated median survival of approximately 3 years from diagnosis $[1,2]$. Our knowledge of the natural history of IPF remains limited. It is recognised that the disease course demonstrates marked and unpredictable inter-patient heterogeneity for reasons that are yet to be determined [1].

Over the past decade, significant advances have been made both in our understanding of the complex signalling pathways involved in disease pathogenesis and in the feasibility of performing large, well-conducted, multicentre, randomised, placebo-controlled trials (RCT).

Previous articles in this series: 1. Cottin V, Camus P: Practical issues and challenges in idiopathic pulmonary fibrosis. Respiration 2013;86:1-4. 2. Poletti V, Ravaglia C, Buccioli M, Tantalocco P, Piciucchi S, Dubini A, Carloni A, Chilosi M, Tomassetti S: Idiopathic pulmonary fibrosis: diagnosis and prognostic evaluation. Respiration 2013;86:5-12. 3. Kenn K, Gloeckl R, Behr J: Pulmonary rehabilitation in patients with idiopathic pulmonary fibrosis - a review. Respiration 2013;86:89-99. 4. Antoniou KM, Wells AU: Acute exacerbations of idiopathic pulmonary fibrosis. Respiration 2013;86:265-274.

\section{KARGER}

E-Mail karger@karger.com

www.karger.com/res c) 2013 S. Karger AG, Basel

0025-7931/13/0865-0353\$38.00/0
Prof. Luca Richeldi

Level E, South Block

University Hospital Southampton

Southampton SO16 6YD (UK)

E-Mail L.Richeldi@soton.ac.uk 
As yet, however, no pharmacological therapy has been shown to prolong survival of patients with IPF. The combined efforts of pharmaceutical companies, patient associations, dedicated physicians and governmentfunded networks, such as the US Idiopathic Pulmonary Fibrosis Clinical Research Network (IPFnet), have facilitated a dramatic increase in the methodological quality, number and size of RCT; this has provided essential insights into trial design, including patient selection and outcome measures, the natural history and the clinical course of IPF. Recent unexpected trial results have, however, emphasised the limits of our understanding of disease-relevant therapeutic targets and the importance of conducting robust RCT for every proposed therapy. Although currently there is no pharmacological therapy universally accepted to modify the disease course of IPF there is cautious optimism that robust evidence to support the use of such a therapy may soon become available.

The aim of this paper is to review the current place of disease-modifying pharmacological therapy in the management of IPF; it will consider therapeutic clinical trials recently completed or in progress and their possible implications on recommended drug therapy, practical issues when applying RCT findings to an individual patient with IPF and trial design challenges as we aim to increase the quality and life expectancy of patients with IPF.

\section{Recent Significant Clinical Trials (2010 Onwards)}

\section{Negative Trials (Either Harmful or Ineffective Therapies)}

Multiple pathways have been implicated in the pathogenesis of IPF, however our understanding of which are relevant therapeutic targets in patients presenting with the disease remains minimal. Currently, to be considered a potential disease-modifying therapy in IPF typically requires a demonstration of efficacy in animal models of pulmonary fibrosis, most often the bleomycin mouse model. The limitations in such models replicating IPF and hence response to treatment are unfortunately illustrated by the significant number of compounds discussed here where promising animal model data have translated into an ineffective or even harmful action in patients. Such unexpected trial results have highlighted that, if we are to follow the principal of 'first, do no harm', every pharmacological therapy should be considered unproven and potentially harmful as a treatment for IPF until there is robust systematic appraisal of safety and efficacy data from phase III RCT.
Given the heterogeneity and complexity of IPF, negative RCT are an inevitable process; however, the recognition that a putative therapy is actually ineffective or potentially even harmful informs pharmacological disease management guidelines, improves trial designs and enables reassessment of our understanding of the relevance of targeting complex pathways proposed to be involved in IPF pathogenesis.

\section{Prednisone, Azathioprine and N-Acetylcysteine: \\ A Study That Evaluates Response in IPF \\ (PANTHER-IPF)}

The combination of the anti-inflammatory agent prednisolone and the cytotoxic agent azathioprine with or without the anti-oxidant $\mathrm{N}$-acetylcysteine (NAC) was the default standard of care for patients with IPF for most of the past decade [3, 4]. In 2005, the Idiopathic Pulmonary Fibrosis International Group Exploring N-Acetylcysteine I Annual (IFIGENIA) study compared 'standard' therapy of prednisolone and azathioprine with or without NAC (so-called 'triple' therapy) in the treatment of IPF [5]. The addition of NAC was found to significantly reduce the rate of decline in vital capacity (VC) and single-breath diffusing capacity of the lung for carbon monoxide (DLCO), so meeting the primary end point. However, there were numerous limitations to this study, including the omission of a placebo-only arm and a significant patient dropout rate, with the consequent need for imputation of a large set of missing data. The IPFnetsponsored PANTHER-IPF RCT was designed to address the true effectiveness of NAC alone and in 'triple' therapy in slowing disease progression in IPF [6]. Patients with IPF and mild-moderatelung function impairment (forced VC, FVC $\geq 50 \%$ and DLCO $\geq 30 \%$ ) were assigned to receive triple therapy, NAC alone or matched placebo for 60 weeks. Following a planned efficacy and safety interim analysis (mean follow-up 32 weeks), the triple therapy arm $(n=77)$ was halted. Although absolute numbers of events were relatively small, compared with the placebo arm $(\mathrm{n}=78)$ statistically significant increased risks of death (11 vs. $1 \%)$, all-cause hospitalisation ( 29 vs. $8 \%)$ and treatment-related serious adverse events (31 vs. 9\%) were seen. The placebo and triple therapy groups had no significant differences in demographic and clinical characteristics. Moreover, no clinical or physiological effect was seen with triple therapy.

This was the first trial to compare triple therapy with placebo and provides clear evidence that, as a treatment for IPF, triple therapy increases risks of death and hospitalisation. The reasons for this, and which components 
might be responsible, remain uncertain. The shortened duration of this trial limits comparison of mortality rates with previous trials when assessing if an aberrant outcome has occurred. Results from the NAC monotherapy and placebo arms are anticipated in early 2014 (ClinicalTrials.gov NCT00650091) with the aim of clarifying whether NAC alone provides any direct anti-fibrotic effect.

\section{The Anti-Coagulant Effectiveness in IPF (ACE-IPF)}

Trial

Based on animal model and human studies [7-11] proposing the importance of the coagulation cascade in pulmonary fibrosis and a small, unblinded, randomized study in Japan suggesting a mortality benefit in patients treated with anti-coagulation [12], the safety and efficacy of warfarin in IPF was investigated in this RCT sponsored by the IPFnet [13]. Patients with progressive IPF (defined as a symptomatic, physiologic or radiological deterioration) were randomized to warfarin or placebo for 48 weeks. Patients who required anti-coagulation for nonIPF-related reasons were excluded. Following an unscheduled interim analysis requested by the study Data and Safety Monitoring Board (mean follow-up 28 weeks) the study was halted. A significantly increased mortality rate (28.1 vs. $6.2 \%)$ was observed in the subjects randomized to warfarin $(n=72)$ compared to placebo $(n=73)$. Respiratory worsening (exacerbation or progression) was the most common feature contributing to the excess mortality in the warfarin group. No significant treatment effects in quality of life measures or physiologic end points were observed.

This study suggests that there is no role for warfarintype anti-coagulants as a treatment for progressive IPF. However, any role of anti-coagulant therapy in acute exacerbations of IPF remains uncertain. The use of warfarin in patients with IPF who have acknowledged indications for anti-coagulation was not addressed in this study.

\section{Bosentan Use in Interstitial Lung Disease (BUILD)-3 Trial}

Endothelin-1, a potent vasoconstrictor and growth factor, has been proposed as a key mediator in IPF [14], and the pro-fibrotic effects of endothelin- 1 can be attenuated in animal models using bosentan, a non-selective endothelin receptor antagonist [15]. A previous trial of bosentan, the Bosentan Use in Interstitial Lung Disease (BUILD)-1 trial [16], whilst not meeting its primary end point of change from baseline in 6-min walk distance, suggested on post hoc analysis a trend to delayed IPF pro- gression or death in patients with surgical lung biopsy specimens demonstrating histological features of usual interstitial pneumonia [17]. Following this post hoc anal$y$ sis, the BUILD-3 trial was designed to further investigate these possible beneficial trends in this IPF subgroup. Patients with IPF of less than 3 years duration with diagnosis confirmed by surgical lung biopsy and less than $5 \%$ honeycombing on baseline high-resolution computed tomography received either bosentan $(n=407)$ or placebo $(\mathrm{n}=209)$. Whilst well tolerated, no significant difference between treatment groups was observed for composite primary end point (death or progression defined by a decline in FVC $\geq 10 \%$ and $\geq 15 \%$ in DLCO or an acute exacerbation of IPF), health-related quality of life or dyspnoea. Small effects favouring bosentan in changes from baseline to 1 year in FVC (0.04 liters) and DLCO were observed. On the basis of these studies, bosentan cannot be considered a treatment option for IPF.

\section{Randomised, Placebo-Controlled Study to Evaluate} the Safety and Effectiveness of Ambrisentan in IPF (ARTEMIS-IPF)

Ambrisentan is a selective endothelin A receptor antagonist that is approved for treatment of patients with pulmonary arterial hypertension [18]. Conceived following the BUILD-1 study and with a pharmacological profile distinct from that of bosentan, patients with IPF aged 40-80 years with minimal or no honeycombing on highresolution computed tomography and baseline right heart catheterization were randomized to ambrisentan or placebo [19]. At $75 \%(n=492)$ of target enrolment, the RCT was terminated after unplanned interim analysis (mean follow-up 34.7 weeks) recommended by the Data Monitoring committee indicating a low likelihood of showing efficacy by the scheduled study end. Compared to the placebo group, ambrisentan-treated patients were significantly more likely to have disease progression (27.4 vs. $17.2 \%$ ) and respiratory hospitalisations (13.4 vs. $5.5 \%$ ), and whilst not statistically significant there were more deaths ( 7.9 vs. $3.7 \%)$ in the active limb. Stratification on the basis of baseline pulmonary hypertension identified similar results. The findings of this study indicate that ambrisentan should not be used as a treatment for IPF regardless of the presence of pulmonary hypertension.

\section{Macitentan Use in an IPF Clinical (MUSIC) Trial}

Macitentan, a novel dual endothelin receptor antagonist, has been proposed to prevent the development of lung fibrosis in a bleomycin-induced rat model of fibrosis [20]. In this RCT, subjects were randomized to maciten- 
$\tan (n=119)$ or placebo $(n=59)$ [21]. Although macitentan was well tolerated, no differences were observed in the primary end point of FVC change at 12 months or secondary end points including time to disease worsening or death, thus proving that macitentan is ineffective in the treatment of IPF.

\section{The Everolimus in IPF Study}

Everolimus, a derivative of rapamycin, is a macrocyclic proliferation signal inhibitor with immunosuppressive and anti-fibroproliferative effects [22-25]. It is a potent inhibitor of in vitro fibroblast proliferation after lung transplantation [26] and markedly reduces bleomycininduced pulmonary fibrosis in the rat model [27]. The safety and efficacy of everolimus in the treatment of IPF was assessed in this RCT in patients with a diagnosis of IPF confirmed by surgical lung biopsy [28]. The everolimus group $(\mathrm{n}=44)$ was associated with more rapid disease progression (defined as deterioration in pulmonary function, mean time 180 days) when compared to placebo ( $\mathrm{n}=45$, mean time to disease progression 450 days). Small initial trial population size combined with significant withdrawal from the study ( $68 \%$ of subjects randomized to everolimus and $27 \%$ of subjects randomized to placebo withdrew from the study during the first 12 months) limits data interpretation, however, this study suggests that everolimus monotherapy is not effective in the treatment of IPF and may be harmful.

\section{Neutral (Studies with Clinical Equipoise)}

Treating Interstitial Pneumonia with the Addition of Co-Trimoxazole

Co-trimoxazole (trimethoprim/sulphamethoxazole) is a sulphonamide antibiotic with immunomodulatory actions [29-31]. On the basis of an observation of clinical improvement in a patient with advanced fibrotic lung disease treated with oral co-trimoxazole and a subsequent small pilot study suggesting improvement in objective measures of function including FVC [32], this RCT was conducted on patients with fibrotic idiopathic interstitial pneumonia (89\% diagnosed as definite/probable IPF) and a Medical Research Council dyspnoea score $\geq 2$ [33]. Subjects were randomized to receive co-trimoxazole $960 \mathrm{mg}$ b.d. $(n=92)$ or placebo $(n=86)$ for 12 months. No difference in the primary end point of change in FVC was seen, nor functional measures such as DLCO, 6-min walk time or Medical Research Council dyspnoea score. Nearly one third of patients receiving co-trimoxazole withdrew due to side effects (primarily nausea and rash). No difference in mortality was identified in the intention to treat analy- sis; however, in a post hoc per protocol analysis of patients adhering to treatment (61\%), a significant reduction in allcause mortality was seen (6 vs. $22 \%$ ), with an associated reduction in frequency of respiratory tract infections and improved quality of life measures. Conflicting with the pilot study [32], no difference in functional measures of disease control was observed. Increased mortality was identified in patients treated with immunosuppression, consistent with the increased mortality demonstrated in the triple therapy arm of the PANTHER-IPF trial [6].

Whether this post hoc finding was a consequence of protection against a previously underappreciated role of bacterial infection in IPF exacerbations and/or progression, prevention of immunosuppression-associated infections or an immunomodulatory effect of co-trimoxazole is unknown. Interpretation of these findings is limited by the heterogeneity of the patients included in this study, the significant side effect-related patient withdrawal and the possible confounding factor of immunosuppression. This study is, however, more likely to represent a 'real-life' population of patients than many other current studies designed to ensure homogeneous patient groupings. Further investigation is warranted into the role of a better-tolerated prophylactic antibiotic regime for patients with advanced fibrotic lung disease.

\section{Sildenafil Trial of Exercise Performance in IPF (STEP-IPF)}

Sildenafil is a phophodiesterase-5 inhibitor, which stabilizes cyclic guanosine monophosphate, the second messenger of nitric oxide, leading to pulmonary vasodilation. It preferentially induces vasodilatation in well-ventilated lung tissue [34], so potentially improving ventilation-perfusion matching and gas exchange in patients with IPF. Small case series of patients with IPF and pulmonary hypertension $[35,36]$ treated with sildenafil suggested improved exercise tolerance and improved quality of life. An RCT of patients with IPF considered to be advanced (DLCO $<35 \%$ of the predicted value) was conducted where they received either sildenafil $(n=89)$ or placebo $(n=91)$ [37]. The primary end point (improvement of at least $20 \%$ in 6-min walk distance at 12 weeks) demonstrated no statistical difference between the sildenafil and the placebo arms. Small but significant differences in secondary outcome including arterial oxygenation, DLCO, degree of dyspnoea and quality of life were, however, seen in those receiving sildenafil. No baseline right-heart catheterization was available for this study and so the prevalence and degree of pulmonary arterial hypertension was unknown or whether this may have confounded trial results. 
A recent post hoc subgroup analysis [38] of 119 (of 180 subjects) baseline echocardiograms does, however, suggest that patients with right ventricular systolic dysfunction on echocardiogram $(n=22)$ treated with sildenafil had an improvement in quality of life and showed a lesser decrement in the 6-min walk distance $(99.3 \mathrm{~m}) \mathrm{com}$ pared with placebo. Further investigation should be considered into whether sildenafil is an effective treatment in patients with advanced IPF and pulmonary hypertension.

\section{Promising Trials (Studies with Possible Evidence of Disease-Modifying or Symptomatic Benefit) \\ To Improve Pulmonary Fibrosis with BIBF 1120 (TOMORROW) Study}

Nintedanib is a tyrosine kinase inhibitor that suppresses signalling receptors, including fibroblast growth factor receptors, platelet-derived growth factor receptors and vascular endothelial growth factor receptors [39]. Activation of these receptors has been implicated in the pathogenesis of fibrosis [40,41], and so inhibition of the receptors has been proposed to slow the progression of IPF $[42,43]$. In this 52 -week phase II RCT of 432 patients [44], the efficacy and safety of 4 doses of nintedanib were compared with placebo in patients with IPF with an FVC $\geq 50 \%$, a DLCO of $30-79 \%$ of predicted and a partial pressure of arterial oxygen when breathing ambient air of $\geq 55 \mathrm{~mm} \mathrm{Hg}$ at altitudes up to $1,500 \mathrm{~m}$. Whilst pre-specified statistical analysis of the primary end point of the annual rate of FVC decline did not differ significantly between the group of patients receiving the highest nintedanib dose (150 mg twice daily) and placebo after statistical correction for multiple comparisons, the difference did approach the threshold for significance $(\mathrm{p}=$ 0.06 ), with a $68 \%$ reduction in the annual rate of decline in FVC compared with placebo (0.06 vs. 0.19 liters). Furthermore, nintedanib was associated with improved health-related quality of life (measured by the St. George's Respiratory Questionnaire) and reduced frequency of acute exacerbations. Compared to placebo, gastrointestinal side effects (diarrhoea, nausea and vomiting) and subclinical increases in liver aminotransferases were more common in patients treated with nintedanib. To further investigate these findings, two concomitant identical 52-week phase III placebo-controlled trials (INPULSIS 1 and 2, ClinicalTrials.gov NCT01335464 and NCT01335477) evaluating the efficacy and safety of nintedanib $150 \mathrm{mg}$ b.d. in patients with IPF with a primary end point of annual rate of decline in FVC have completed recruitment (total enrolment 1,066) and are anticipated to report in early 2014.
Clinical Studies Assessing Pirfenidone in IPF:

Research of Efficacy and Safety Outcomes

(CAPACITY)

Pirfenidone is an orally administered pyridine that has combined anti-inflammatory, anti-oxidant and anti-fibrotic actions in experimental models of pulmonary fibrosis, although the precise mechanism of action is unknown [45-50]. Regulation of transforming growth factor $\beta$ in vitro, and inhibition of fibroblast and collagen synthesis in animal models of lung fibrosis has been demonstrated [46, 49, 51, 52]. Following a phase II RCT [53] which identified a reduction in the rate of decline in $\mathrm{VC}$ and frequency of acute exacerbations in patients treated with pirfenidone, three phase III RCT were conducted. In a Japanese phase III RCT [54], pirfenidone was administered in a $2: 1: 2$ ratio $(1,800$ or $1,200 \mathrm{mg} /$ day, or placebo) to 275 patients. The primary end point was changed prior to unblinding to change in VC over 52 weeks. A significant difference in VC decline between the placebo $(-0.16$ liters) and the high dose pirfenidone group ( -0.09 liters), and improved progression-free survival time was observed.

The CAPACITY studies were two almost identical multinational RCT (trials 004 and 006) conducted to confirm the efficacy of pirfenidone in reducing decline in lung function of patients with IPF with mild-moderate impairment in lung function (FVC of 35-90\%, DLCO of $50-90 \%$ and a 6 -min walk test distance of at least $150 \mathrm{~m}$ ) [55]. Subjects were randomised to receive pirfenidone or placebo for 72 weeks. The primary end point was change in percentage of predicted FVC from baseline to week 72 . In study 004 , patients were assigned in a 2:1:2 ratio to pirfenidone $2,403 \mathrm{mg} /$ day $(\mathrm{n}=174)$, pirfenidone 1,197 $\mathrm{mg} /$ day $(\mathrm{n}=87)$ or placebo $(\mathrm{n}=174)$; in study 006 , patients were assigned in a 1:1 ratio to pirfenidone 2,403 $\mathrm{mg} /$ day $(\mathrm{n}=171)$ or placebo $(\mathrm{n}=173)$. In study 004 , 2,403 $\mathrm{mg}$ /day pirfenidone reduced decline in FVC, with an absolute difference in FVC of $4.4 \%$ in the high-dose group compared to placebo at 72 weeks; the $1,197 \mathrm{mg} /$ day group was intermediate to that in the $2,403 \mathrm{mg} /$ day pirfenidone and placebo groups. In study 006, however, no significant difference in FVC at 72 weeks between placebo and pirfenidone arms was identified $(\mathrm{p}=0.501)$. Treatment was discontinued because of adverse events in $15 \%$ of patients treated with pirfenidone compared to $9 \%$ treated with placebo. Most commonly reported side effects were gastrointestinal (nausea, dyspepsia, vomiting and anorexia), skin disorders (rash and photosensitivity) and dizziness. 
In a pre-specified pooled analysis, pirfenidone (compared to placebo) reduced decline in FVC (absolute difference in FVC 2.5\% at 72 weeks; $\mathrm{p}<0.005$ ), prolonged progression-free survival by $26 \%$ and reduced mean decline in 6-min walk distance at 72 weeks. A Cochrane meta-analysis of the data from the three phase III trials identifies that treatment with pirfenidone reduces the risk of disease progression by $30 \%$ (hazard ratio, $0.70,95 \%$ confidence interval 0.56-0.88) [56].

\section{Thalidomide: Treatment of Chronic Cough in IPF}

A prominent feature of IPF, affecting up to $80 \%$ of patients, for which no effective therapies have previously been identified, is a persistent, non-productive, often disabling cough [57-59]. During open-label clinical trial evaluation of thalidomide as an IPF treatment, a marked reduction in cough was observed [60]. Thalidomide is a potent immunomodulatory, anti-inflammatory and antiangiogenic drug [61-63]. This single-centre, 24-week, double-blind, 2-treatment, 2-period crossover trial was designed to further investigate this finding in patients with clinical history consistent with IPF and chronic cough lasting $>8$ weeks [64]. Thalidomide $(\mathrm{n}=12)$ significantly improved cough in patients with IPF and overall respiratory quality of life compared to placebo $(n=12)$. Adverse events (typically constipation, dizziness or malaise) were, however, reported in $74 \%$ of patients receiving thalidomide compared with $22 \%$ receiving placebo. These findings suggest that thalidomide may be an effective therapy for symptomatic treatment of chronic cough in patients with IPF; however, this was a small single-centre trial and thalidomide has been associated with the development of acute interstitial lung processes [65-68] and thromboembolic events [69]. Further multi-centre studies are therefore essential to confirm both safety and efficacy of thalidomide in the treatment of chronic cough in IPF.

\section{Current Disease-Modifying Pharmacological Therapy}

Individual patient management in IPF is primarily based on the recommendations of scientific societies, such as the 2011 joint statement of the American Thoracic Society, European Respiratory Society, Japanese Respiratory Society and Latin American Thoracic Association [1], which proposed guidelines on the pharmacologic and non-pharmacologic approaches to patient management based on the GRADE system. This is an evidence-based methodology which rates the quality of available evidence and strength of recommendation following literature searches and assessment of the available information [70]. NAC monotherapy, anti-coagulation, combined NAC and azathioprine and prednisolone, and pirfenidone, all received weak recommendations against their use; the accompanying interpretation suggested these therapies should not be used in the majority of patients with IPF, but may be a reasonable choice in a minority of patients. Pharmacologic therapy for IPF was considered to be without any definite, evidence-based benefit, and lung transplantation was the only intervention strongly recommended given its proven survival benefit in IPF [71]. In appropriate patients, enrolment in a clinical trial and/or lung transplantation was therefore recommended; however, these options are feasible for less than half of the patients for RCT and $<1 \%$ for transplant [72]. The guideline committee proposed to update treatment recommendations when new and pertinent high-quality evidence regarding the use of treatments becomes available for scientific review. This process is now ongoing as recent trials provide important new evidence, which is likely to significantly impact on future recommendations (summarised in table 1): this illustrates the difficulty of providing widely applied robust comprehensive long-term guidelines in a new era of phase III trials that have the potential to substantially change clinical practice.

At present, there is no scientific evidence to suggest that current therapeutic strategies can reverse fibrosis in IPF; the realistic goal of therapies under investigation is to stabilize or reduce the rate of disease progression. It is therefore a substantial achievement that pirfenidone is now approved for use in Japan, Europe, India and Canada following regulatory appraisal of the data investigating efficacy and tolerability. This treatment was not approved by the US FDA due to concerns including a perceived lack of efficacy as measured by change in FVC and lack of survival benefit in analysis of the data considered by them. As a consequence, a further phase III trial with the aim of providing supporting data further, ASCEND (ClinicalTrials.gov NCT 01366209), was commenced with results anticipated in early 2014. In the same period, the phase III NAC (PANTHER) and nintedanib (INPULSIS 1 and 2) trials are also expected to report. A significant update to the current evidence base is therefore awaited soon.

Until these results are published in peer-reviewed journals and systematically appraised, in regions where it is approved, the commencement of pirfenidone 
Table 1. Summary of recent or ongoing clinical trials of pharmacologic therapies potentially considered for prescription to patients with IPF according to current ATS/ERS guidelines

\begin{tabular}{|c|c|c|c|c|c|}
\hline $\begin{array}{l}\text { Agent/ } \\
\text { treatment }\end{array}$ & $\begin{array}{l}\text { Potential } \\
\text { mechanism of } \\
\text { action }\end{array}$ & $\begin{array}{l}\text { Current ATS/ERS/JRS/ALAT } \\
\text { GRADE recommendation [13] }\end{array}$ & Trial/trial design & $\begin{array}{l}\text { Duration of trial and } \\
\text { primary end point }\end{array}$ & Outcome of trial \\
\hline $\begin{array}{l}\text { NAC } \\
\text { monotherapy }\end{array}$ & Anti-oxidant & Weakly negative & $\begin{array}{l}\text { PANTHER-IPF } \\
\text { (ClinicalTrials.gov NCT } \\
\text { 00650091); design as } \\
\text { described above }\end{array}$ & $\begin{array}{l}\text { Change in FVC over } 60 \\
\text { weeks }\end{array}$ & $\begin{array}{l}\text { Awaited; anticipated to report } \\
\text { in early } 2014\end{array}$ \\
\hline Pirfenidone & $\begin{array}{l}\text { Anti-fibrotic; } \\
\text { direct } \\
\text { mechanism of } \\
\text { action } \\
\text { unknown }\end{array}$ & Weakly negative & $\begin{array}{l}\text { CAPACITY studies (004 } \\
\text { and 006) [13]; } 2 \\
\text { multi-centre phase III } \\
\text { RCT (pirfenidone vs. } \\
\text { placebo) in patients with } \\
\text { IPF with mild-moderate } \\
\text { impairment in lung } \\
\text { function (FVC of } 35-90 \% \text {, } \\
\text { and DLCO of } 50-90 \% \text { ) }\end{array}$ & $\begin{array}{l}\text { Change in FVC over } 72 \\
\text { weeks }\end{array}$ & $\begin{array}{l}\text { Study } 004 \text { met the primary end } \\
\text { point, with reduced decline in } \\
\text { FVC vs. placebo at } 72 \text { weeks; in } \\
\text { study } 006 \text {, there was no } \\
\text { significant difference between } \\
\text { arms; pre-specified pooled } \\
\text { analysis identified that } \\
\text { pirfenidone reduced decline in } \\
\text { FVC (absolute difference in } \\
\text { FVC } 2.5 \% \text {; p = 0.005); a further } \\
\text { phase III trial, ASCEND } \\
\text { (ClinicalTrials.gov NCT } \\
\text { 01366209) is anticipated to } \\
\text { report in early } 2014\end{array}$ \\
\hline
\end{tabular}

ATS = American Thoracic Society; ERS = European Respiratory Society; JRS = Japanese Respiratory Society; ALAT = Latin American Thoracic Association.

should be discussed with patients with mild-moderate IPF. They should be fully informed of the rationale including the potential slowing in decline in lung function but that no survival or quality of life benefit has been demonstrated; a treatment decision can then reached with the patient based on their specific values and preferences.

Oral NAC remains widely prescribed, given perceived safety and tolerability, however, the results of the PANTHER trial are awaited for any clear evidence of a diseasemodifying effect, and at present there are no data to reassess the current weak recommendation against its use. If either NAC or pirfenidone is commenced, then the question of whether to use them in combination arises. A phase II safety and tolerability study of this combination, the PANORAMA trial, has recently commenced (EudraCT No. 2012-000564-14), however, this will not be sufficiently powered to address the issue of combination efficacy. Still, it will provide relevant information on the tolerability of the combined treatment and potential pharmacological interactions. 


\section{Practical Challenges: Applying Disease-Modifying Pharmacological Therapy to the Individual IPF Patient}

In this series, Poletti et al. [73] have highlighted the significant inter-patient heterogeneity associated with disease pattern and rate of progression in IPF. A similarly variable and as yet unpredictable response to pharmacological therapies would be anticipated. Many recent RCT as discussed above have attempted to select a homogeneous population of patients considered to have mildmoderate IPF (typically defined as an FVC between 50 and $90 \%$ of predicted and DLCO between 30 and $90 \%$ of predicted). When an RCT does demonstrate diseasemodifying effects, the question then arises of how this can be applied to an individual patient with IPF. Although patients enrolled in trials are homogeneous in terms of their lung function, they may not be similar in terms of the rate of progression of their disease. If a patient on treatment were not to progress, given the current inability to predict disease course, it would be uncertain if this was simply a benign disease course or a treatment-related effect; in clinical practice, a potentially life-long therapy would be extremely difficult to discontinue.

National prescription guidelines are being informed by clinical trial criteria. In the United Kingdom, pirfenidone has been recommend by the National Institute for Health and Care Excellence [74] for patients with an FVC between 50 and $80 \%$ of predicted. Is it ethically justifiable to exclude patients not meeting these criteria, in particular as these arbitrary values can be dramatically impacted by frequently concomitant conditions such as pulmonary emphysema?

As in any other disease, patients excluded from trials typically include those not meeting the trial diagnostic criteria of IPF, patients with mild/early disease and lung function parameters above trial cut-offs, patients with concurrent emphysema/chronic obstructive pulmonary disease and patients with advanced disease. Any attempts to translate efficacy from an RCT to patients not meeting entry criteria is often based on extrapolation and clinical judgement. If such patient groups are to be considered for treatment then any disease-modifying effect must be extrapolated from trial data. It is conceivable that an antifibrotic therapy that slows disease progression would have the greatest efficacy when used in patients at an early stage of the disease. As very mild patients are excluded from trials, there is, however, no supporting evidence of this.
It is uncertain if patients with advanced disease will respond to anti-fibrotic therapies or what unintended impact therapies with non-insignificant side effect profiles might cause. Some applicable data may arise from nonblinded, non-randomised extensions of RCT for therapies believed to demonstrate efficacy, such as the RECAP extension study of pirfenidone. It is essential that universal registries are collated for every patient commencing a disease-modifying therapy, thus increasing understanding of the role of such therapies outside of their trial criteria over time.

Pirfenidone typically causes gastrointestinal (dyspepsia, diarrhoea and anorexia) and dermatological (photosensitivity) side effects [55]. In the absence of a proven survival or quality of life benefit, the question arises of what is an acceptable side effect profile for a potentially life-long therapy. In already functionally limited patients, such side effects may have a significant impact on quality of life; this reinforces the importance of developing validated tools to assess quality of life in such patients.

We have yet to define what constitutes a failure to respond to a treatment in IPF and hence consider ceasing therapy. It would be clinically appropriate to discontinue a treatment when it is considered not to be working. In the United Kingdom, the National Institute for Health and Care Excellence have recommended that pirfenidone is discontinued if over a 12-month period there is evidence of disease progression on treatment (defined as a decrease in predicted $\mathrm{FVC} \geq 10 \%$ ); no guidance is provided for whether this is an absolute or relative change [75]. It is uncertain if this represents a clinically meaningful treatment failure; as this may or may not coincide with a functional or symptomatic decline, we are unable to predict the disease course of an individual, we do not know what the rate of decline may have been without treatment and are unable to answer whether the withdrawal of treatment may provoke a precipitous decline. Given the many existing uncertainties, it might be reasonable using a comprehensive approach in clinical practice, such as one based on the lung functional data, supported by other activity measures, quality of life and highresolution computed tomography changes.

In this era of rapid change, there are therefore significant challenges to clinicians wishing to provide up-todate best practice care for individual patients. A number of approaches may aid in this. Firstly, patients with known or suspected interstitial lung disease (ILD) in the context of primary care should be referred promptly to a specialist ILD centre, as delayed access to tertiary care is associated with a higher risk of death in IPF independent of 
disease severity or co-morbidities [76]. This provides patients access to concentrated expertise in diagnosis and comprehensive management, including disease-modifying therapy initiation, monitoring, side effect control and non-pharmacological support. Secondly, a formal full multi-disciplinary team meeting encompassing physicians, radiologists, pathologists and nurse specialists with expertise in ILD must determine consensus diagnosis and proposed treatment strategies for every patient; as we enter an era of potential combination therapies, this will become increasingly important. Although there has been no validation of the accuracy or reproducibility of consensus based on a multi-disciplinary team diagnosis until better biomarkers of disease are developed its role is essential. Thirdly, given the significant heterogeneity in patients with IPF and varying individual patient values and preferences, an individualised treatment approach is paramount. Any patient not meeting the criteria for prescribing guidelines or not representative of the patients enrolled in clinical trials must be fully counselled regarding the rationale for considering a disease-modifying therapy and the inherent uncertainties outside of trial criteria; clinician patient engagement is vital to reach an individual treatment decision. If a patient is fully informed and wishes to commence treatment then a clear agreement must be reached of how and at what time frame the benefits of continuing treatment will be assessed. Finally, recognising the current relatively modest benefits of any disease-modifying therapy, a significant focus must be on providing an integrated approach encompassing the physician, ILD nurse specialist and patient support groups to address psychosocial needs and to provide best supportive care, including pulmonary rehabilitation (reviewed in detail in this series by Kenn et al. [77]), oxygen therapy, pharmacological symptom relief and end-of-life care.

\section{RCT Design}

We are in the first stages of the development of clinical trial methodology in IPF. Recent trials have highlighted the importance of consistent trial design and the number of methodological challenges yet to be fully addressed. A comprehensive review of this area was recently published [78]. A number of important issues will, however, need to be considered. Among others, rigorous studies to validate non-invasive biomarkers to guide treatment commencement and for monitoring response represent a priority. Differences in the evaluation of efficacy of drugs across different regulatory agencies in the world will need to be

analysed and understood in order to avoid the potential for ethical disparities in the treatment of IPF patients at a global level. The input from dedicated statistical teams will be critically important for the interpretation of trial results, given the unavoidable rate of drop-offs (in particular when dealing with patients with advanced disease). The imputation of missing data is a crucial step for interpreting results of trials and it is of concern that so far many and different statistical methodologies have been used in various trials.

In the rapidly changing IPF landscape, it is predictable that more and more drugs will be approved for use: will then placebo-controlled trials still be feasible? Looking at other respiratory diseases (e.g. chronic obstructive pulmonary disease), this should be still ethically acceptable, but this issue will need a specific discussion and hopefully an international consensus. Finally, considering the need for a holistic approach to a disease like IPF, nonpharmacological therapies (e.g. psychological interventions, supportive and palliative measures or pulmonary rehabilitation) will need to be properly assessed in the context of specifically designed RCT.

\section{Conclusions}

We are evolving from a period of ineffective and potentially harmful empiric treatments to one of mechanism-based anti-fibrotic therapies proven by large RCT to modify disease progression. How we address the methodological and ethical challenges of conducting research in an era of combination therapies and apply these therapies to the practical long-term management of individual patients with IPF will determine our success in increasing both their length and quality of life.

References

Respiration 2013;86:353-363 DOI: $10.1159 / 000356958$
1 Raghu G, Collard HR, Egan JJ, Martinez FJ, Behr J, Brown KK, et al: An official ATS/ERS/ JRS/ALAT statement: idiopathic pulmonary fibrosis: evidence-based guidelines for diagnosis and management. Am J Respir Crit Care Med 2011;183:788-824.

-2 Ley B, Collard HR, King TE: Clinical course and prediction of survival in idiopathic pulmonary fibrosis. Am J Respir Crit Care Med 2011;183:431-440.

3 American Thoracic Society. Idiopathic pulmonary fibrosis: diagnosis and treatment. International consensus statement. American Thoracic Society (ATS), and the European Respiratory Society (ERS). Am J Respir Crit Care Med 2000;161:646-664. 
$\checkmark 4$ Wells A, Hirani N: Interstitial lung disease guideline. Thorax 2008;63:v1-v58.

5 Demedts M, Behr J, Buhl R, Costabel U, Dekhuijzen R, Jansen HM, et al: High-dose acetylcysteine in idiopathic pulmonary fibrosis. N Engl J Med 2005;353:2229-2242.

-6 The Idiopathic Pulmonary Fibrosis Clinical Research Network: Prednisone, azathioprine, and $\mathrm{N}$-acetylcysteine for pulmonary fibrosis. N Engl J Med 2012;366:1968-1977.

-7 Scotton CJ, Krupiczojc MA, Königshoff M, Mercer PF, Lee YCG, Kaminski N, et al: Increased local expression of coagulation factor $\mathrm{X}$ contributes to the fibrotic response in human and murine lung injury. J Clin Invest 2009;119:2550-2563.

8 Hubbard RB, Smith C, Le Jeune I, Gribbin J, Fogarty AW: The association between idiopathic pulmonary fibrosis and vascular disease. Am J Respir Crit Care Med 2008;178: 1257-1261.

-9 Günther A, Lübke N, Ermert M, Schermuly RT, Weissmann N, Breithecker A, et al: Prevention of bleomycin-induced lung fibrosis by aerosolization of heparin or urokinase in rabbits. Am J Respir Crit Care Med 2003;168: 1358-1365.

10 Günther AA, Mosavi PP, Ruppert CC, Heinemann SS, Temmesfeld BB, Velcovsky HGH, et al: Enhanced tissue factor pathway activity and fibrin turnover in the alveolar compartment of patients with interstitial lung disease. Thromb Haemost 2000;83:853-860.

$\checkmark 11$ Sode BF, Dahl M, Nielsen SF, Nordestgaard BG: Venous thromboembolism and risk of idiopathic interstitial pneumonia. Am J Respir Crit Care Med 2010;181:1085-1092.

12 Kubo H, Nakayama K, Yanai M, Suzuki T, Yamaya M, Watanabe M, et al: Anticoagulant therapy for idiopathic pulmonary fibrosis. Chest 2005;128:1475-1482.

-13 Noth I, Anstrom KJ, Calvert SB, de Andrade J, Flaherty KR, Glazer C, et al: A placebo-controlled randomized trial of warfarin in idiopathic pulmonary fibrosis. Am J Respir Crit Care Med 2012;186:88-95.

-14 Fonseca C, Abraham D, Renzoni EA: Endothelin in pulmonary fibrosis. Am J Respir Cell Mol Biol 2010;44:1-10.

15 Park SH, Saleh D, Giaid A, Michel RP: Increased endothelin-1 in bleomycin-induced pulmonary fibrosis and the effect of an endothelin receptor antagonist. Am J Respir Crit Care Med 1997;156:600-608.

16 King TE Jr, Behr J, Brown KK, du Bois RM, Lancaster L, de Andrade JA, et al: BUILD-1: a randomized placebo-controlled trial of bosentan in idiopathic pulmonary fibrosis. Am J Respir Crit Care Med 2008;177:75-81.

17 King TE Jr, Brown KK, Raghu G, du Bois RM, Lynch DA, Martinez F, et al: BUILD-3: a randomized, controlled trial of bosentan in idiopathic pulmonary fibrosis. Am J Respir Crit Care Med 2011;184:92-99.

18 Galie N, Olschewski H, Oudiz RJ, Torres F, Frost A, Ghofrani HA, et al: Ambrisentan for the treatment of pulmonary arterial hyperten- sion: results of the ambrisentan in pulmonary arterial hypertension, randomized, doubleblind, placebo-controlled, multicenter, efficacy (ARIES) study 1 and 2. Circulation 2008; 117:3010-3019.

$>19$ Raghu G, Behr J, Brown KK, Egan JJ, Kawut SM, Flaherty KR, et al: Treatment of idiopathic pulmonary fibrosis with ambrisentan: a parallel, randomized trial. Ann Intern Med 2013;158:641-649.

20 Landskroner K, Rey M, Wanner D, Hess P, Clozel M, Iglarz M: Optimization of tissue targeting properties of macitentan, a new dual endothelin receptor antagonist, improves its efficacy in a rat model of pulmonary fibrosis associated with pulmonary arterial hypertension. Am J Respir Crit Care Med 2011; 183:A6445.

21 Raghu G, Million-Rousseau R, Morganti A, Perchenet L, Behr J, MUSIC study group: Macitentan for the treatment of idiopathic pulmonary fibrosis: the randomised controlled MUSIC trial. Eur Respir J 2013, DOI: 10.1183/09031936.00104612.

22 Böhler T, Waiser J, Budde K, Lichter S, Jauho A, Fritsche L, et al: The in vivo effect of rapamycin derivative SDZ RAD on lymphocyte proliferation. Transplant Proc 1998;30:2195-2197.

23 Schuler W, Sedrani R, Cottens S, Häberlin B, Schulz M, Schuurman HJ, et al: SDZ RAD, a new rapamycin derivative: pharmacological properties in vitro and in vivo. Transplantation 1997;64:36-42.

24 Nair RV, Huang X, Shorthouse R, Adams B, Brazelton T, Braun-Dullaeus R, et al: Antiproliferative effect of rapamycin on growth factor-stimulated human adult lung fibroblasts in vitro may explain its superior efficacy for prevention and treatment of allograft obliterative airway disease in vivo. Transplant Proc 1997;29:614-615.

25 Nishimura T, Faul JL, Berry GJ, Veve I, Pearl RG, Kao PN: 40-O-(2-hydroxyethyl)-rapamycin attenuates pulmonary arterial hypertension and neointimal formation in rats. Am J Respir Crit Care Med 2001;163:498-502.

26 Azzola A, Havryk A, Chhajed P, Hostettler K, Black J, Johnson P, et al: Everolimus and mycophenolate mofetil are potent inhibitors of fibroblast proliferation after lung transplantation. Transplantation 2004;77:275-280.

27 Simler NR, Howell DCJ, Marshall RP, Goldsack NR, Hasleton PS, Laurent GJ, et al: The rapamycin analogue SDZ RAD attenuates bleomycin-induced pulmonary fibrosis in rats. Eur Respir J 2002;19:1124-1127.

28 Malouf MA, Hopkins P, Snell G, Glanville AR: An investigator-driven study of everolimus in surgical lung biopsy confirmed idiopathic pulmonary fibrosis. Respirology 2011; 16:776-783.

29 Stegeman CA, Tervaert JW, de Jong PE, Kallenberg CG: Trimethoprim-sulfamethoxazole (co-trimoxazole) for the prevention of relapses of Wegener's granulomatosis. Dutch Co-Trimoxazole Wegener Study Group. N Engl J Med 1996;335:16-20.
30 Anderson R, Grabow G, Oosthuizen R, Theron A, Van Rensburg AJ: Effects of sulfamethoxazole and trimethoprim on human neutrophil and lymphocyte functions in vitro: in vivo effects of co-trimoxazole. Antimicrob Agents Chemother 1980;17:322-326.

31 Hess DA, O'Leary EF, Lee JT, Almawi WY, Madrenas J, Rieder MJ: Inhibition of cytokine production and interference in IL-2 receptormediated Jak-Stat signaling by the hydroxylamine metabolite of sulfamethoxazole. FASEB J 2001;15:1855-1857.

32 Varney VA, Parnell HM, Salisbury DT, Ratnatheepan S, Tayar RB: A double blind randomised placebo controlled pilot study of oral co-trimoxazole in advanced fibrotic lung disease. Pulm Pharmacol Ther 2008;21:178-187.

-33 Shulgina L, Cahn AP, Chilvers ER, Parfrey H, Clark AB, Wilson EC, et al: Treating idiopathic pulmonary fibrosis with the addition of cotrimoxazole: a randomised controlled trial. Thorax 2013;68:155-162.

-34 Ghofrani HA, Wiedemann R, Rose F, Schermuly RT, Olschewski H, Weissmann N, et al: Sildenafil for treatment of lung fibrosis and pulmonary hypertension: a randomised controlled trial. Lancet 2002;360:895-900.

35 Collard HR, Anstrom KJ, Schwarz MI, Zisman DA: Sildenafil improves walk distance in idiopathic pulmonary fibrosis. Chest 2007; 131:897-899.

36 Madden BP, Allenby M, Loke T-K, Sheth A: A potential role for sildenafil in the management of pulmonary hypertension in patients with parenchymal lung disease. Vascul Pharmacol 2006;44:372-376.

37 Idiopathic Pulmonary Fibrosis Clinical Research Network, Zisman DA, Schwarz M, Anstrom KJ, Collard HR, Flaherty KR, et al: A controlled trial of sildenafil in advanced idiopathic pulmonary fibrosis. N Engl J Med 2010;363:620-628.

38 Han MK, Bach DS, Hagan PG, Yow E, Flaherty KR, Toews GB, et al: Sildenafil preserves exercise capacity in patients with idiopathic pulmonary fibrosis and right-sided ventricular dysfunction. Chest 2013;143:1699.

39 Hilberg F, Roth GJ, Krssak M, Kautschitsch S, Sommergruber W, Tontsch-Grunt $\mathrm{U}$, et al: BIBF 1120: triple angiokinase inhibitor with sustained receptor blockade and good antitumor efficacy. Cancer Res 2008;68:4774-4782.

40 Coward WR, Saini G, Jenkins G: The pathogenesis of idiopathic pulmonary fibrosis. Ther Adv Respir Dis 2010;4:367-388.

41 Allen JT, Spiteri MA: Growth factors in idiopathic pulmonary fibrosis: relative roles. Respir Res 2002;3:13.

42 Abdollahi A, Li M, Ping G, Plathow C, Domhan S, Kiessling F, et al: Inhibition of plateletderived growth factor signaling attenuates pulmonary fibrosis. J Exp Med 2005;201:925-935.

43 Chaudhary NI, Roth GJ, Hilberg F, MullerQuernheim J, Prasse A, Zissel G, et al: Inhibition of PDGF, VEGF and FGF signalling attenuates fibrosis. Eur Respir J 2007;29:976985. 
44 Richeldi L, Costabel U, Selman M, Kim D, 55 Noble PW, Albera C, Bradford WZ, Costabel Hansell D, Nicholson A, et al: Efficacy of a tyrosine kinase inhibitor in idiopathic pulmonary fibrosis. N Engl J Med 2011;365:10791087.

-45 Nakayama S, Mukae H, Sakamoto N, Kakugawa T, Yoshioka S, Soda H, et al: Pirfenidone inhibits the expression of HSP47 in TGF- $\beta 1$ stimulated human lung fibroblasts. Life Sci 2008;82:210-217.

46 Lee B, Margolin S, Nowak R: Pirfenidone: a novel pharmacological agent that inhibits leiomyoma cell proliferation and collagen production. J Clin Endocrinol Metab 1998;83: 219-223.

-47 Kakugawa T, Mukae H, Hayashi T, Ishii H, Abe K, Fujii T, et al: Pirfenidone attenuates expression of HSP47 in murine bleomycininduced pulmonary fibrosis. Eur Respir J 2004;24:57-65.

-48 Schaefer CJ, Ruhrmund DW, Pan L, Seiwert SD, Kossen K: Antifibrotic activities of pirfenidone in animal models. Eur Respir Rev 2011;20:85-97.

49 Oku H, Shimizu T, Kawabata T, Nagira M, Hikita I, Ueyama A, et al: Antifibrotic action of pirfenidone and prednisolone: different effects on pulmonary cytokines and growth factors in bleomycin-induced murine pulmonary fibrosis. Eur J Pharmacol 2008;590:400408.

50 Nakazato H, Oku H, Yamane S, Tsuruta Y, Suzuki R: A novel anti-fibrotic agent pirfenidone suppresses tumor necrosis factor-alpha at the translational level. Eur J Pharmacol 2002;446:177-185.

51 Iyer SN, Gurujeyalakshmi G, Giri SN: Effects of pirfenidone on transforming growth factor-beta gene expression at the transcriptional level in bleomycin hamster model of lung fibrosis. J Pharmacol Exp Ther 1999;291:367373.

52 Iyer SN, Gurujeyalakshmi G, Giri SN: Effects of pirfenidone on procollagen gene expression at the transcriptional level in bleomycin hamster model of lung fibrosis. J Pharmacol Exp Ther 1999;289:211-218.

-53 Azuma A, Nukiwa T, Tsuboi E, Suga M, Abe S, Nakata K, et al: Double-blind, placebo-controlled trial of pirfenidone in patients with idiopathic pulmonary fibrosis. Am J Respir Crit Care Med 2005;171:1040-1047.

-54 Taniguchi H, Ebina M, Kondoh Y, Ogura T, Azuma A, Suga M, et al: Pirfenidone in idiopathic pulmonary fibrosis. Eur Respir J 2010; 35:821-829. U, Glassberg MK, Kadatzke D, et al: Pirfenidone in patients with idiopathic pulmonary fibrosis (CAPACITY): two randomised trials. Lancet 2011;377:1760-1769.

56 Spagnolo P, Del Giovane C, Luppi F, Cerri S, Balduzzi S, Walters EH, et al: Non-steroid agents for idiopathic pulmonary fibrosis. Cochrane Database Syst Rev 2010;9:CD003134.

57 Ryerson CJ, Abbritti M, Ley B, Elicker BM, Jones KD, Collard HR: Cough predicts prognosis in idiopathic pulmonary fibrosis. Respirology 2011;16:969-975.

58 Hope-Gill BDM, Hilldrup S, Davies C, Newton RP, Harrison NK: A study of the cough reflex in idiopathic pulmonary fibrosis. Am J Respir Crit Care Med 2003;168:995-1002.

59 Brown KK: Chronic cough due to chronic interstitial pulmonary diseases: ACCP evidence-based clinical practice guidelines. Chest 2006;129:180S-185S.

60 Horton MR, Danoff SK, Lechtzin N: Thalidomide inhibits the intractable cough of idiopathic pulmonary fibrosis. Thorax 2008;63: 749-749.

61 Eisen T, Boshoff C, Mak I, Sapunar F, Vaughan MM, Pyle L, et al: Continuous low dose thalidomide: a phase II study in advanced melanoma, renal cell, ovarian and breast cancer. Br J Cancer 2000;82:812-817.

62 Singhal S, Mehta J, Desikan R, Ayers D, Roberson P, Eddlemon P, et al: Antitumor activity of thalidomide in refractory multiple myeloma. N Engl J Med 1999;341:1565-1571.

63 Figg WD, Dahut W, Duray P, Hamilton M, Tompkins A, Steinberg SM, et al: A randomized phase II trial of thalidomide, an angiogenesis inhibitor, in patients with androgenindependent prostate cancer. Clin Cancer Res 2001;7:1888-1893.

64 Horton MR, Santopietro V, Mathew L, Horton KM, Polito AJ, Liu MC, et al: Thalidomide for the treatment of cough in idiopathic pulmonary fibrosis: a randomized trial. Ann Intern Med 2012;157:398-406.

65 Pretz J, Medeiros BC: Thalidomide-induced pneumonitis in a patient with plasma cell leukemia: no recurrence with subsequent lenalidomide therapy. Am J Hematol 2009;84: 698-699.
66 Sasaki M, Isobe Y, Tsukune Y, Kawahara S, Hamano Y, Ando J, et al: Thalidomide may induce interstitial pneumonia preferentially in Japanese patients. Eur J Haematol 2009;82: 73-74.

67 Tilluckdharry L, Dean R, Farver C, Ahmad M: Thalidomide-related eosinophilic pneumonia: a case report and review of the literature. Cases J 2008;1:143.

68 Carrión Valero F, Bertomeu González V: Toxicidad pulmonar por talidomida. Arch Bronconeumol 2002;38:492-494.

69 Alkindi S, Dennison D, Pathare A: Arterial and venous thrombotic complications with thalidomide in multiple myeloma. Arch Med Res 2008;39:257-258.

70 Schünemann HJ, Jaeschke R, Cook DJ, Bria WF, El-Solh AA, Ernst A, et al: An official ATS statement: grading the quality of evidence and strength of recommendations in ATS guidelines and recommendations. Am J Respir Crit Care Med 2006;174:605-614.

-71 Thabut G, Mal H, Castier Y, Groussard O, Brugière O, Marrash-Chahla R, et al: Survival benefit of lung transplantation for patients with idiopathic pulmonary fibrosis. J Thorac Cardiovasc Surg 2003;126:469-475.

72 Nathan SD, Shlobin OA, Weir N, Ahmad S, Kaldjob JM, Battle E, et al: Long-term course and prognosis of idiopathic pulmonary fibrosis in the new millennium. Chest 2011;140: 221-229.

73 Poletti V, Ravaglia C, Buccioli M, Tantalocco P, Piciucchi S, Dubini A, et al: Idiopathic pulmonary fibrosis: diagnosis and prognostic evaluation. Respiration 2013;86:5-12.

74 National Institute for Health and Care Excellence: Pirfenidone for treating idiopathic pulmonary fibrosis. Natl Inst Health Care Excellence 2013;TA282:1-64.

75 Richeldi L, Ryerson CJ, Lee JS, Wolters PJ, Koth LL, Ley B, et al: Relative versus absolute change in forced vital capacity in idiopathic pulmonary fibrosis. Thorax 2012;67:407-411.

76 Lamas DJ, Kawut SM, Bagiella E, Philip N, Arcasoy SM, Lederer DJ: Delayed access and survival in idiopathic pulmonary fibrosis. Am J Respir Crit Care Med 2011;184:842-847.

77 Kenn K, Gloeckl R, Behr J: Pulmonary rehabilitation in patients with idiopathic pulmonary fibrosis - a review. Respiration 2013;86: 89-99.

78 Cerri S, Del Giovane C, Balduzzi S, Soncini F, Sdanganelli A, Richeldi L: New approaches to the design of clinical trials in idiopathic pulmonary fibrosis. Clin Invest 2013;3:531-544. 